\title{
Variations of Frequency Responses
} of a Cable-Stayed Bridge and Calculation of the Damping Coefficient of Selected Vibration Modes Based on the Data Recorded with Radar Systems**

\section{Introduction}

Determination of the frequency response during acceptance measurements is usually based on the vibrations of the test structure, which may be regarded as free vibrations. The determined modes of vibration are one of the basic criteria for the assessment of the technical condition of a bridge structure, or for the possibility of accepting a newly constructed bridge and, consequently, allowing traffic validation [1]. There are numerous ways to measure the vibration of bridge spans [3-5]. Popular techniques based on the measurement of acceleration are not always optimal for long spans (often occurring low frequencies of normal modes of vibration). Accurate and efficient inductive sensors assure good results, but they require a direct access to the test span, which is not a problem with respect to viaducts, while it poses a serious limitation when surveying bridges.

The technique which is based on the terrestrial radar interferometry allows for a remote, non-contact measurement, as well as the recording of a bridge behavior. Despite its one-dimensional nature, the measurement offers a lot of advantages: high frequency of displacement recording, simultaneous measurement of many elements, operation range greater than the length of the bridge spans or height of the pylons implemented in Poland. The result of the measurement could be a time series representing changes in the length of the vector: radar unit-structural element, or the frequency spectrum of these changes. Therefore, it is possible to record and analyze changes in the shape of bridge spans triggered off by static loads, as well as to record dynamic responses.

* AGH University of Science and Technology, Faculty of Mining Surveying and Environmental Engineering, Department of Engineering Surveying and Civil Engineering, Krakow, Poland

** The study was carried out with financial support from the grant no. 15.11.150.241/13, AGH University of Science and Technology 


\section{Test Bridge Structure}

The research was carried out during the test load of a bridge located within the provincial road No. 956. The bridge structure consists of a four-span load-bearing structure, two spans are suspended on one pylon with steel cables. Platforms have a beam and slab structure. The presented results refer to the response of a longer suspended span with a theoretical length of 105 meters (Fig. 1).

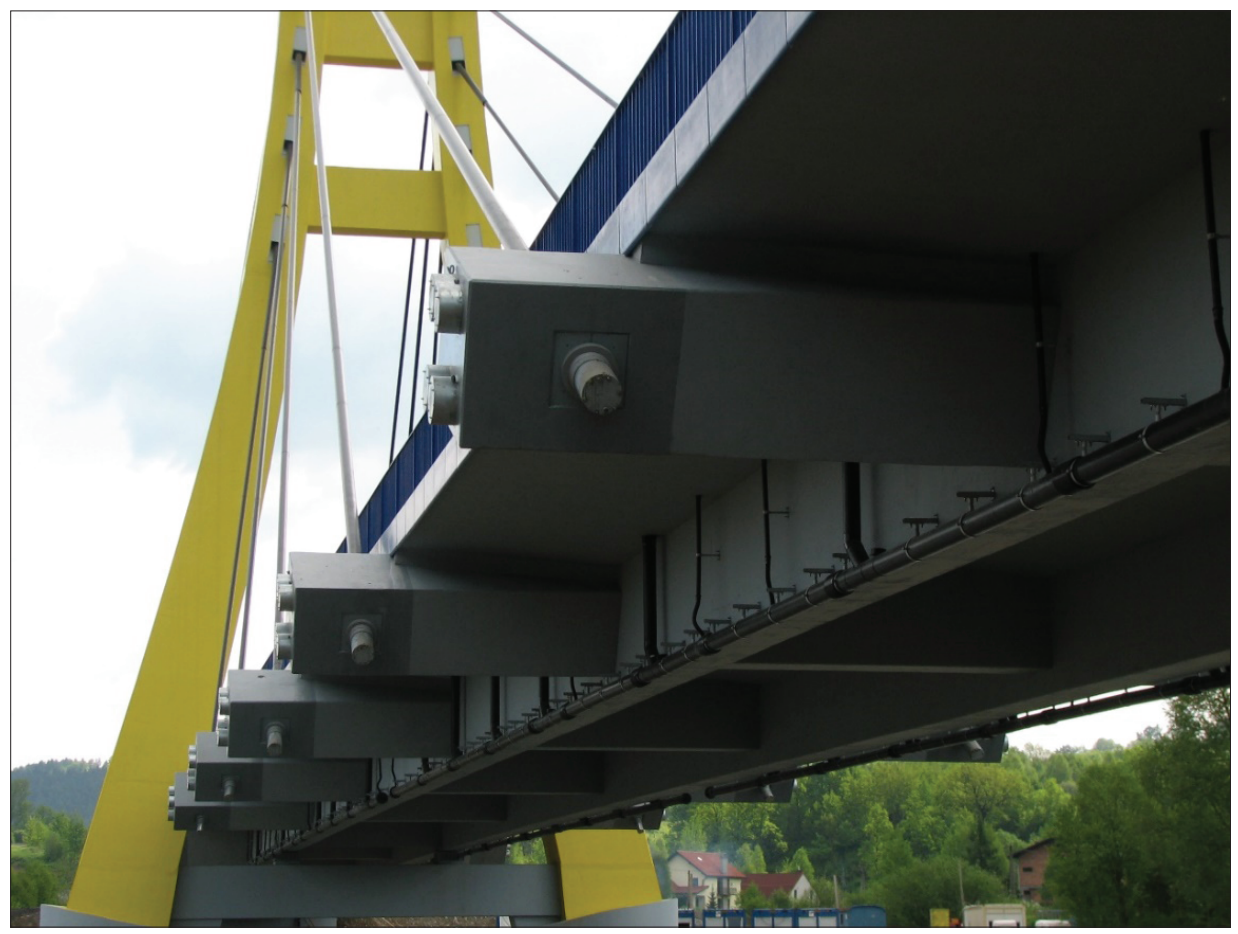

Fig. 1. The span of the bridge measured with a radar system (radar unit located next to the pylon)

The test carried out confirmed in practice the presence of the vibration frequency predicted in theory, when the inductive sensor LVDT was used for the measurement [2]. The Table 1 shows an example of the comparison of the results of the radar and induction systems, on the background of the expected frequencies from the modal analysis. It should be emphasized that, in this comparison, the structure is treated as a whole (as in the case of the modal analysis), and the radar as well as the induction systems simultaneously examined the responses of different spans. Additionally, the set of results is very rich and diversified, and it strongly depends on the used excitation (which will be discussed below). 
Table 1. Comparison of modal analysis (MA), radar interferometry (IBIS) and inductive sensor (LVDT)

\begin{tabular}{|c|c|c|c|}
\hline $\begin{array}{c}\text { Number of vibration } \\
\text { mode }\end{array}$ & MA [Hz] & IBIS [Hz] & LVDT [Hz] \\
\hline 1 & 0.58 & 0.72 & 0.72 \\
\hline 2 & 0.93 & - & 1.14 \\
\hline 3 & 1.09 & 1.10 & 1.24 \\
\hline 4 & 1.43 & - & 1.31 \\
\hline 5 & 1.54 & 1.60 & 1.59 \\
\hline 6 & 1.73 & 1.66 & 1.70 \\
\hline 7 & - & 1.82 & - \\
\hline 8 & 1.92 & - & 1.87 \\
\hline 9 & 1.96 & 1.96 & 2.07 \\
\hline 10 & 2.45 & - & 2.63 \\
\hline 11 & 2.53 & - & 2.69 \\
\hline 12 & 2.58 & - & 3.06 \\
\hline 13 & 3.11 & 2.92 & 3.46 \\
\hline 14 & 3.41 & 3.42 & 3.82 \\
\hline 15 & 3.58 & - & \\
\hline
\end{tabular}

Source: [2]

In each case, frequency identification was accompanied by calculating the logarithmic damping decrement.

\section{Spectral Analysis}

Dynamic loads were carried out by the passage of one or two trucks (symmetrically or from the right side of the bridge, looking west), braking or leap over the threshold (Tab. 2 - column 3). Four measurement points corresponding to the crossbeams of the longest span were analyzed. These points were located at a distance of 11, 26.5, 42.5 and 59 meters from the radar unit (in the radar profile, the corresponding measurement points (Rbin) are the points no. 22, 53, 85 and 118). The analysis focused on the first eight modes of the vibration. Table 2 presents the results of the spectral analysis for the selected data sets. It should be emphasized that the Table shows the subsequent frequencies detected for a given data set. It is therefore possible that a similar frequency will be the second one for one set, and the fourth one for another set (Tab. 2). In other words, Table 2 shows the subsequently detected frequencies. 
Table 2. Detected frequencies

\begin{tabular}{|c|c|c|c|c|c|c|c|c|c|c|c|}
\hline \multirow{2}{*}{$\begin{array}{l}\text { Speed } \\
{[\mathrm{km} / \mathrm{h}]}\end{array}$} & \multirow{2}{*}{ Direction } & \multirow{2}{*}{ Load } & \multirow{2}{*}{ Rbin } & \multicolumn{8}{|c|}{ Detected frequency [Hz] } \\
\hline & & & & 1 & 2 & 3 & 4 & 5 & 6 & 7 & 8 \\
\hline \multirow{11}{*}{50} & $\mathrm{~W}$ & \multirow{10}{*}{2} & 22 & 0.72 & 1.84 & 2.90 & - & - & - & - & - \\
\hline & $E$ & & 22 & - & 1.84 & 2.86 & 3.44 & - & - & - & - \\
\hline & $\mathrm{W}$ & & 53 & 0.72 & 1.84 & 2.90 & & - & - & - & - \\
\hline & $E$ & & 53 & - & 1.84 & 2.86 & 3.44 & - & - & - & - \\
\hline & W & & 85 & 0.72 & 1.66 & 2.90 & - & - & - & - & - \\
\hline & E & & 85 & - & - & - & 3.36 & - & - & - & - \\
\hline & $\mathrm{W}$ & & 118 & 0.72 & 1.14 & 1.60 & 1.96 & 2.90 & - & - & - \\
\hline & E & & 118 & - & 1.70 & 2.86 & 3.06 & - & - & - & - \\
\hline & $\mathrm{W}$ & & 154 & 0.72 & 1.72 & 2.00 & 2.92 & - & - & - & - \\
\hline & $E$ & & 154 & 0.94 & - & 2.22 & 2.88 & - & - & - & - \\
\hline & $\mathrm{W}$ & \multirow{9}{*}{1 right } & 22 & 0.72 & 1.84 & 2.92 & 3.28 & - & - & - & - \\
\hline \multirow{8}{*}{70} & W & & 53 & 0.74 & - & - & 3.30 & - & - & - & - \\
\hline & $E$ & & 53 & 0.72 & - & - & 3.32 & - & - & - & - \\
\hline & $W$ & & 85 & 0.72 & - & - & - & - & - & - & - \\
\hline & E & & 85 & 0.74 & - & - & - & - & - & - & - \\
\hline & W & & 118 & 0.74 & - & 2.92 & - & - & - & - & - \\
\hline & $E$ & & 118 & 0.72 & - & - & - & - & - & - & - \\
\hline & $\mathrm{W}$ & & 154 & & & & & & & & \\
\hline & E & & 154 & & & & & & & & \\
\hline \multirow{14}{*}{ braking } & E & \multirow{14}{*}{1} & 22 & 0.72 & - & - & - & - & - & - & - \\
\hline & $W$ & & 22 & 0.72 & 1.85 & 2.90 & - & - & - & - & - \\
\hline & $\mathrm{E}$ & & 22 & 0.72 & 1.60 & 1.85 & - & - & - & - & - \\
\hline & $\mathrm{E}$ & & 53 & 0.72 & - & 1.94 & - & 3.32 & - & - & - \\
\hline & W & & 53 & 0.72 & 1.85 & 3.35 & 6.68 & 10.01 & 13.36 & 16.69 & 20.05 \\
\hline & $\mathrm{E}$ & & 53 & 0.72 & 1.12 & 1.60 & 3.32 & 6.68 & - & - & - \\
\hline & $\mathrm{E}$ & & 85 & 0.72 & - & - & - & - & 4.84 & - & - \\
\hline & $\mathrm{W}$ & & 85 & 0.72 & - & 1.92 & - & - & & - & - \\
\hline & E & & 85 & 0.70 & 1.12 & 1.47 & 1.85 & - & 4.83 & - & - \\
\hline & E & & 118 & 0.72 & 1.66 & & - & - & - & - & - \\
\hline & W & & 118 & 0.72 & 1.12 & 1.85 & - & - & - & - & - \\
\hline & E & & 118 & 0.72 & 1.26 & 1.60 & 1.85 & 2.82 & 3.73 & - & - \\
\hline & $E$ & & 154 & - & - & - & 2.10 & 3.42 & - & - & - \\
\hline & $W$ & & 154 & 0.72 & 1.10 & 1.77 & 2.27 & - & - & - & - \\
\hline \multirow{7}{*}{ leap } & $\mathrm{E}$ & \multirow{7}{*}{ sill } & 22 & 0.72 & - & 1.82 & - & 3.44 & & 4.46 & \\
\hline & $W$ & & 22 & - & - & - & - & - & - & - & - \\
\hline & E & & 53 & 0.72 & - & 1.80 & - & 3.36 & 6.68 & 10.04 & 13.42 \\
\hline & $\mathrm{W}$ & & 53 & 0.74 & - & 1.71 & - & 3.31 & - & - & - \\
\hline & W & & 85 & 0.72 & 1.14 & 1.60 & 1.88 & - & - & - & - \\
\hline & $\mathrm{W}$ & & 118 & 0.72 & - & - & 2.06 & - & - & - & - \\
\hline & $\mathrm{E}$ & & 154 & - & 0.92 & 1.88 & - & 3.44 & - & - & - \\
\hline
\end{tabular}


Due to the large amount of calculations, Table 2 presents an analysis only of a certain set of data. Blanks indicate that for a given set of data it was not possible to detect the frequency. A total of 97 data sets were analyzed. Each of them could potentially include all 15 modes of vibration identified in the modal analysis carried out on the theoretical model in the test load project. This is due to the fact that the selected Rbins were not in the vibration nodes.

The study was limited to the first eight modes. This makes a total of 776 measurement time series. The analysis found that the actual results enabling the identification of the frequencies were obtained in the 176 time series. In these samples, a time series subjected to the spectral analysis proved the existence of a frequency which was above the level of measurement noise.

The first mode of vibration revealed in the frequency range of $0.72-0.74 \mathrm{~Hz}$ was identified in 51 cases. Other modes (as seen in Table 2) are not identifiable as often.

Attention should be paid to three important facts:

- first of all, there are data sets, based on which none of the frequencies predicted in the theoretical modal analysis can be identified. In other words, some passages of the trucks (treated as a dynamic impulse) did not allow to record any response of the structure with the radar;

- secondly, there are no data sets which allow us to identify all vibration modes;

- thirdly, the identified modes of vibration do not correspond exactly with the theoretically calculated ones.

\section{Determining the Damping Coefficient}

Data obtained from the radar for a sample measurement point (here: for Rbin 53) have been shown in Figure 2. This time series represents the platform free vibration after the exciting force has been eliminated - in this case, after the truck has driven out of the span. Such a time series consists of the interference of all modes of vibration, as well as measurement errors and noise. In practical terms, however, the most interesting is to find an answer to how quickly a given mode of vibration for the observed structural element is damped (suppressed). A parameter which allows to estimate the damping rate is the damping coefficient, based on which the logarithmic damping decrement is calculated. Prior to the calculation aimed at determining the damping coefficient, it is necessary to filter correctly the measurement signal.

Figure 3 presents the measurement of the after using the band-pass filter designed to capture the first mode of the vibration corresponding to the frequency of $0.72 \mathrm{~Hz}$. 


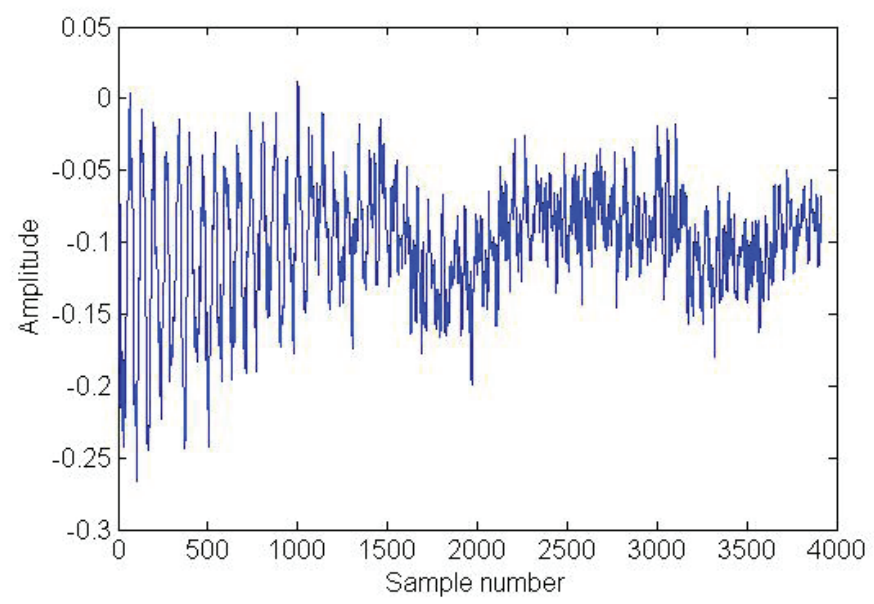

Fig. 2. Raw measurement data

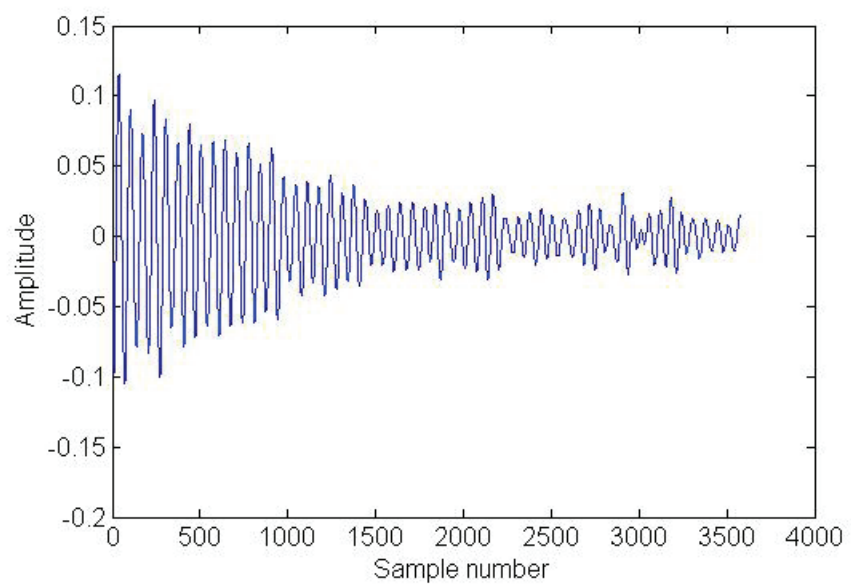

Fig. 3. Measurement data after filtration

The filtered data (in this case the number of samples amounted to 3,500) allow to estimate the damping coefficient. In the ideal case, the time series should match the following relationship:

where:

$$
x(t)=A \cdot e^{-\beta t} \cdot \sin (\omega t+\theta)
$$

$A$ - amplitude,

$\beta$-damping coefficient,

$\omega$ - angular frequency,

$\theta$ - phase shift. 
Due to the inaccuracy of the measurement system, the effect of the use of digital filters and the nature of the studied phenomenon, practical estimation of the $\beta$ coefficient is reduced, for example, to using an approximation model (Fig. 4). The analyzed example, calculated with non-linear regression using the method of least squares, allowed for the estimation of the equation (1) coefficients (with 95\% confidence intervals) at the following level:

$$
\begin{aligned}
& A=-0.1033(-0.1047,-0.1020), \\
& \beta=0.0008083(0.0007931,0.0008235), \\
& \omega=0.09397(0.09395,0.09398), \\
& \theta=1.089(1.076,1.102) .
\end{aligned}
$$

Levenberg-Marquardt algorithm was used for the approximation. The above coefficients were calculated based on the approximation of a set: amplitude - sample number.

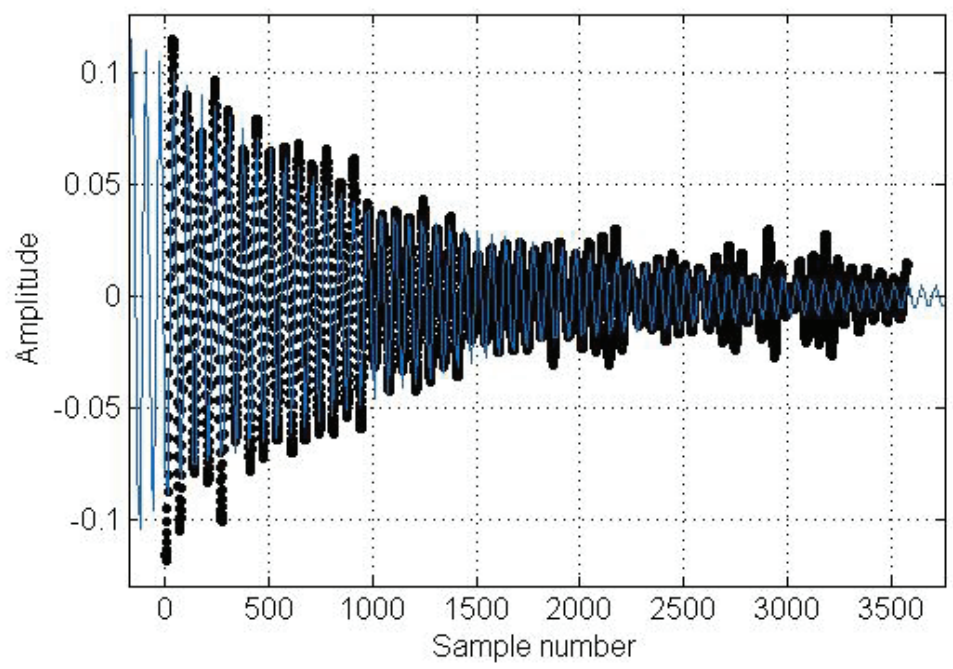

Fig. 4. Approximation

Analogous calculations performed for a set of amplitudes in the time domain give the following results:Coefficients (with $95 \%$ confidence bounds):

$$
\begin{aligned}
& A=0.1025(0.1012,0.1038), \\
& \beta=0.0393(0.0385,0.0400), \\
& \omega=4.6030(4.602,4.603), \\
& \theta=-1.960(-1.973,-1.947) .
\end{aligned}
$$

Naturally, both approaches lead to the same result in terms of determining the logarithmic damping decrement $A=0.0535$. In this case, the logarithmic damping 
decrement has been calculated by multiplying the coefficient $\beta$ and the period of damped vibrations. An independent calculation method based on the Hilbert transform presented in [2] gives very similar results.

\section{Summary}

Conducting research of bridge structures under a test load is an experiment that allows for a practical verification of the adopted calculation model. Although these tests involve a large engagement, they allow to gain important, practically verified, knowledge about the structure. As it appears from the analysis of the data obtained using ground-based interferometric radar, the response of a structure to excitations, depending on their type, is very different. The largest recorded differences between the mathematical model assumed a priori and the measurement results can be noticed within the first three modes of vibration. Only about $23 \%$ of the recorded time series from the rich set of measurement information provides a possibility to detect frequencies. The efficiency of recording time series that allows us to determine the logarithmic damping decrement is even lower.

\section{References}

[1] General Directorate for National Roads and Motorways: Recommendations for tests on road bridges under test load. Attachment to Ordinance No. 35 of the General Directorate for National Roads and Motorways, Warsaw 2008.

[2] Gocał J., Ortyl Ł., Owerko T., Kuras P., Kocierz R., Ćwiąkała P., Puniach E., Sukta O., Bałut A.: Determination of displacement and vibrations of engineering structures using ground-based radar interferometry. Wydawnictwa AGH, Krakow 2013.

[3] Kohut P., Holak K., Uhl T., Krupiński K., Owerko T., Kuraś P.: Structure's condition monitoring based on optical measurements. Key Engineering Materials, vol. 518, 2012, pp. 338-349.

[4] Łaziński P., Salamak M.: Działalność Katedry Dróg i Mostów w badaniach mostów pod próbnym obciażeniem. Inżynieria i Budownictwo, r. 66, nr 5-6, 2010, pp. 300-303.

[5] Pradelok S.: Dynamic tests of certain lattice girder railway bridge type nodes. International Conference on Experimental Vibration Analysis for Civil Engineering Structures EVACES '09, Wroclaw, 14-16 October 2009, pp. 221-222. 